\title{
Novel approach to reduce SARS-CoV-2 transmission during trans-oral robotic surgery
}

\author{
Velda Ling-Yu Chow ${ }^{1}$ (i) - Jimmy Yu-Wai Chan ${ }^{1}$ (D) Melody Man-Kuen Wong ${ }^{1} \cdot$ Stanley Thian-Sze Wong ${ }^{1}$. \\ Raymond King-Yin Tsang ${ }^{1}$
}

Received: 26 November 2020 / Accepted: 17 January 2021 / Published online: 6 February 2021

(c) The Author(s), under exclusive licence to Springer-Verlag London Ltd. part of Springer Nature 2021

\begin{abstract}
This study describes a novel approach in the reduction of SARS-CoV-2 transmission during trans-oral robotic surgery (TORS). Eight patients underwent TORS between 01 February 2020 and 07 September 2020. A sterile plastic sheet draped over sterile supports with water-tight seal around each cannula was used to create a sterile working space within which the robotic arms could freely move during operation. This set-up acts as an additional physical barrier against droplet and aerosol transmission. Operative diagnosis; droplet count and distribution on plastic sheet and face shields of console and assistant surgeons, and scrub nurse were documented. TORS tumour excision was performed for patients with suspected tonsillar tumour $(n=3)$ and tongue base tumour $(n=2)$. TORS tonsillectomy and tongue base mucosectomy was performed for cervical nodal metastatic carcinoma of unknown origin $(n=3)$. Droplet contamination was noted on all plastic drapes $(n=8)$. Droplet contamination was most severe over the central surface at $97.2 \%$ (91.7-100.0\%), with the highest droplet count along the centre-most column where it overlies the site of operation in the oral cavity $33.3 \%(n=31)$. Droplet count decreased towards the periphery. Contamination rate was $2.8 \%(0.0-8.3 \%)$ over the right lateral surface. There was no droplet contamination over the vertex and left lateral surface of plastic drapes. No droplet contamination was noted on face shields of all parties. The use of sterile plastic drapes with water-tight seal around each robotic cannula can help reduce viral transmission to healthcare providers during TORS.
\end{abstract}

Keywords Trans-oral robotic surgery $\cdot$ Head and neck cancer $\cdot$ COVID-19 $\cdot$ SARS-CoV-2 transmission · Novel approach

\section{Introduction}

In the current era of minimally invasive surgery, early tumours in the nasopharynx, oropharynx, larynx and hypopharynx can be safely resected via the oral cavity using robotic surgical systems, obviating the need for external scars, maxillary swing, mandibulotomy and laryngectomy; reducing side-effects associated with radical radiotherapy + / - chemotherapy; and promoting treatment de-intensification in selected patients [1-4].

The novel coronavirus disease 2019 (COVID-19) is caused by SARS-CoV-2 virus. SARS-CoV-2 is found in high abundance in the upper aerodigestive tract mucosa most

Velda Ling-Yu Chow

vlychow@gmail.com

1 Division of Head and Neck Surgery, Department of Surgery, Queen Mary Hospital, The University of Hong Kong, 102 Pokfulam Road, Hong Kong, People's Republic of China notably in the nasopharynx and oropharynx [5]. Patients may be asymptomatic at the time of presentation [6]. There is currently no accurate way of diagnosis [7]. Viral transmission is via close contact and droplets. Airborne transmission may occur during aerosol generating procedures (AGP). [8] World Health Organisation (WHO), Centres for Disease Control and Prevention (CDC) and Centre for Health Protection in Hong Kong (CHP) recommend full barrier protection when performing AGP for unknown, suspected and confirmed COVID-19 patients in order to avoid disease transmission to health care providers. However, as the number of COVID-19 infected patients increases worldwide, there is a global shortage of personal protective equipment (PPE) [8-10]. Hence as head and neck surgeons, we are at particular risk of becoming infected when treating patients during the COVID-19 pandemic.

This study describes a novel approach which aims to decrease viral transmission when performing trans-oral robotic surgery (TORS) during the COVID-19 pandemic. 


\section{Methods}

All patients who underwent TORS in the Division of Head and Neck Surgery of the Department of Surgery, The University of Hong Kong between 01 February 2020 and 07 September 2020 were included.

All patients underwent work-up for tumour staging. These included clinical and endoscopic examination with biopsy taken for histological confirmation; ultrasonography of the neck $+/-$ fine needle aspiration for cytology of suspected neck nodal metastasis; magnetic resonance imaging (MRI) + / - whole-body positron emission tomography (PET) scans.

As recommended by CHP and hospital infection control unit, admission to head and neck surgical ward was only allowed (1) on declaring absence of travel history 14 days prior to surgery, (2) absence of close contact with confirmed cases, and (3) tympanic body temperature $<37.5$ degrees Celsius taken at ward entrance. On admission, routine bloods including white cell count and chest X-ray were checked. Two sets of polymerase chain reaction (PCR) test for nucleic acid sequence homology in nasopharyngeal and throat swabs taken $24 \mathrm{~h}$ apart would only be tested for febrile and symptomatic patients $+/$ - radiological changes on chest X-ray.

All operations were performed by a consultant surgeon experienced in head and neck robotic surgery, accompanied by one surgical assistant who has completed his/ her fellowship training in head and neck surgery and is licensed to perform head and neck robotic surgical procedures, one scrub nurse who is familiar with the robotic surgical procedures, and one consultant anaesthetist. Full barrier protection was adopted by all parties, including goggles, N95 respirator, face shield, gowns and gloves.

After nasal-tracheal intubation by anaesthetist, skin was prepared and draped with disposable surgical drapes (3 M Hong Kong) in the usual manner for TORS, exposing the oral cavity, bilateral neck and sternal notch. A Fr 16 Nelaton catheter was inserted via the remaining nostril for suction of saliva, secretions and any aerosols generated intra-operatively. The Nelaton catheter was connected to a surgical suction system connected to smoke and high-efficiency particulate air (HEPA) filters. Boyle-Davis retractor was used for exposure of the oropharynx and was fixed to patient's left bedside. Docking of Da Vinci Xi Robotic System (Intuitive Surgical Inc., Sunnyvale, CA, USA) and deployment of endowrists was performed trans-orally consisting of a threedimensional high-definition camera, Maryland forceps and Spatula. Omni-tract ${ }^{\circledR}$ FastSystem ${ }^{\circledR}$ Standard Wishbone ${ }^{\circledR}$ Frame 4020 (Integra LifeSciences Corporation, Ohio, USA) was positioned cranial to patient's vertex and fixed to patient's left bedside using the Omni-Flex ${ }^{\circledR}$ Post (Integra LifeSciences Corporation, Ohio, USA) (Fig. 1).

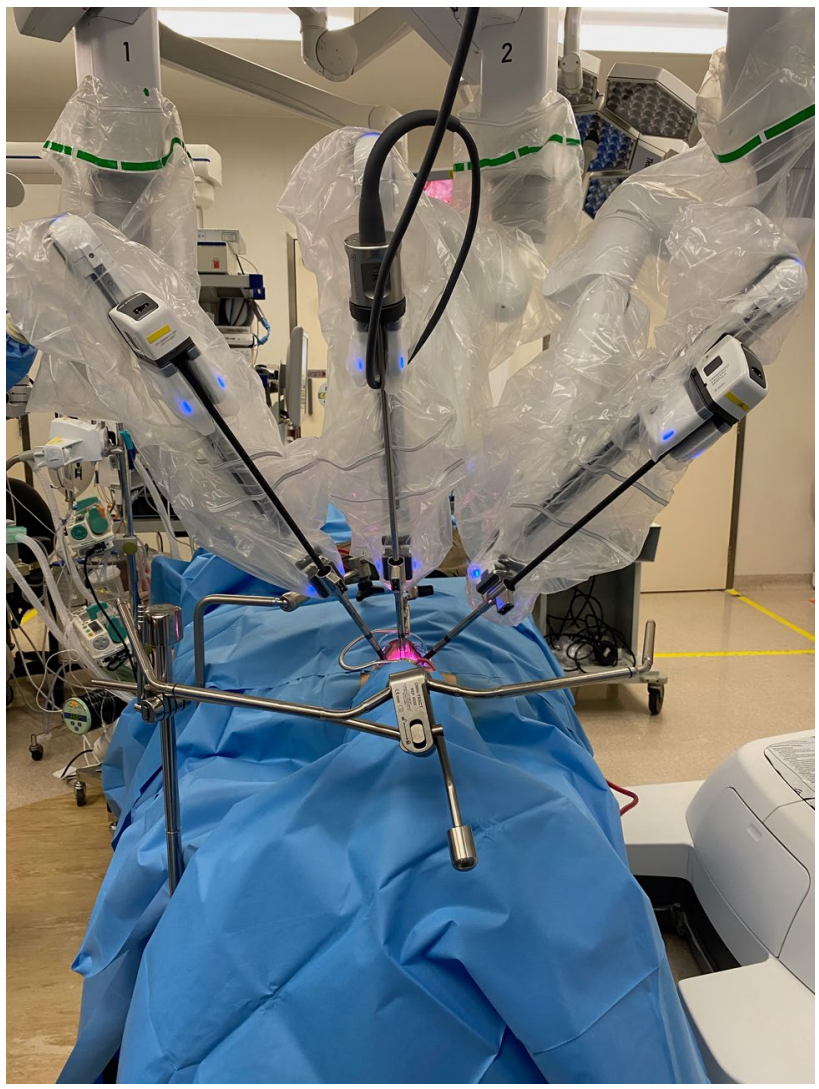

Fig. 1 Placement of Wishbone ${ }^{\circledR}$ Frame and Omni-Flex ${ }^{\circledR}$ Post after docking for TORS

Two clear and sterile plastic sheets, each measuring 120 $\mathrm{cm} \times 140 \mathrm{~cm}$ was draped over the operating field: one plastic sheet was secured to the Wishbone frame with four sterile clips so that the free edge of the sheet reached the caudal half of all three robotic canulae; using adhesive $3 \mathrm{M}$ tape the second plastic sheet was taped to the free edge of the first plastic sheet. Additional adhesive $3 \mathrm{M}$ tape was used to create a water-tight seal at three-point junctions between the two plastic sheets and each of the three robotic cannulae. The free edge of the second sheet was then draped loosely over the Boyle-Davis suspension bar and taped to surgical drapes over the caudal, left and cranial ends using adhesive $3 \mathrm{M}$ tape, leaving the right side untapped for the surgical assistant to work under (Fig. 2). A $1 \mathrm{~cm}$ fenestration was made over the left upper corner of the central operating field for placement of a surgical suction system connected to smoke and HEPA filters. The fenestration was sealed and tubing secured with Tegaderm (3 M Hong Kong). Scrub nurse was position opposite the assistant surgeon's right hand. TORS resection of oropharyngeal pathology was performed in the usual manner by the consultant surgeon at the surgeon's console. 


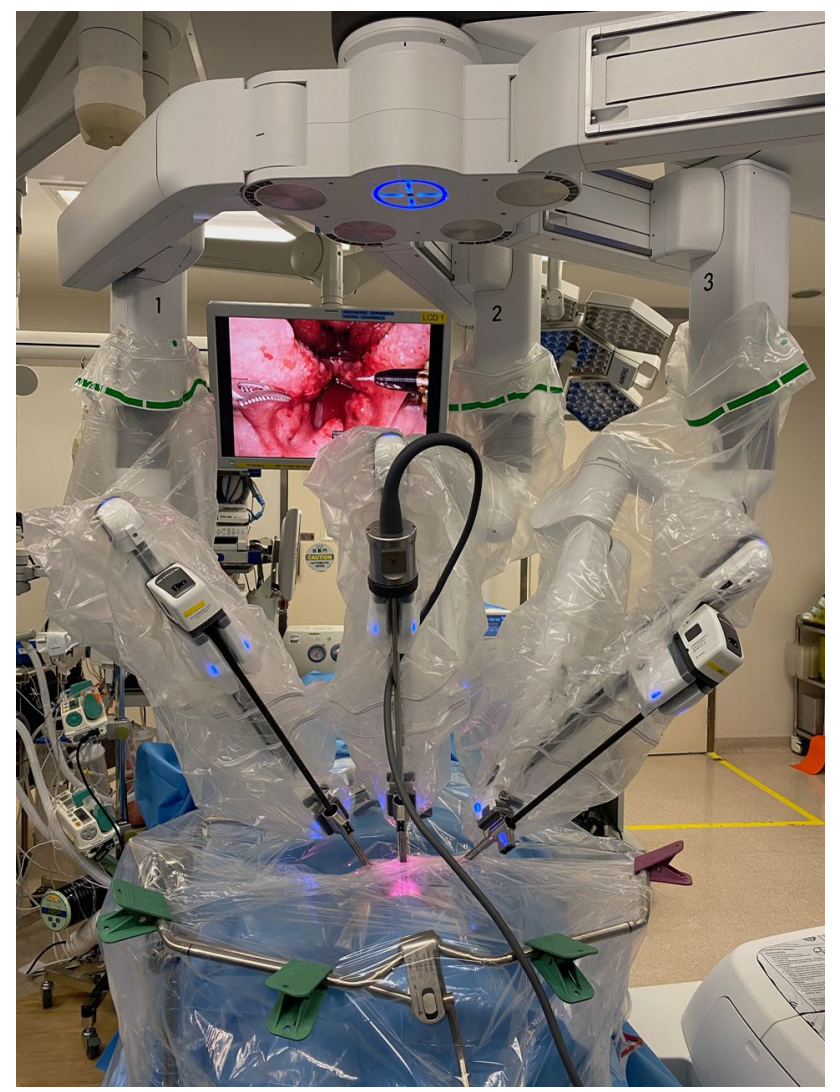

Fig. 2 Placement of 2 sterile plastic sheets over the operative field. The cranial sheet was fixed with 4 sterile clamps on the Wishbone ${ }^{\circledR}$ Frame. The two sheets were taped together using adhesive $3 \mathrm{M}$ tape. Additional adhesive $3 \mathrm{M}$ tape was used to create a water-tight seal at three-point junctions between the two plastic sheets and each of the three robotic cannulae

On completion of TORS, the plastic sheet was pulled taut, and the central, vertex and bilateral surfaces of the plastic sheet were marked with $7 \mathrm{~cm} \times 7 \mathrm{~cm}$ grids (Figs. 3, 4). The face shield of the operating surgeon prior to commencing console surgery; and face shields of both the assistant surgeon and scrub nurse post-operation were retrieved. The face shield used was a piece of optically clear, latex free plastic film measuring $32 \mathrm{~cm}$ in length and $22 \mathrm{~cm}$ in width with foam forehead cushion and elastic strap (A R Medicom Inc (Asia) Ltd.). It covered a full face length from forehead to neck, with outer edges of the face shield reaching bilateral ears. It had anti-fog and anti-glare properties with no hearing restrictions. Each face shield was put against a white background with 12 grids measuring $7 \mathrm{~cm} \times 7 \mathrm{~cm}$ each to facilitate counting at maximal magnification [11]. Each plastic sheet was carefully removed and placed against a white background for counting. The number and size of droplets splashed in each grid of the plastic sheet and face shield was counted using the surgical microscope Leica M720 0H5

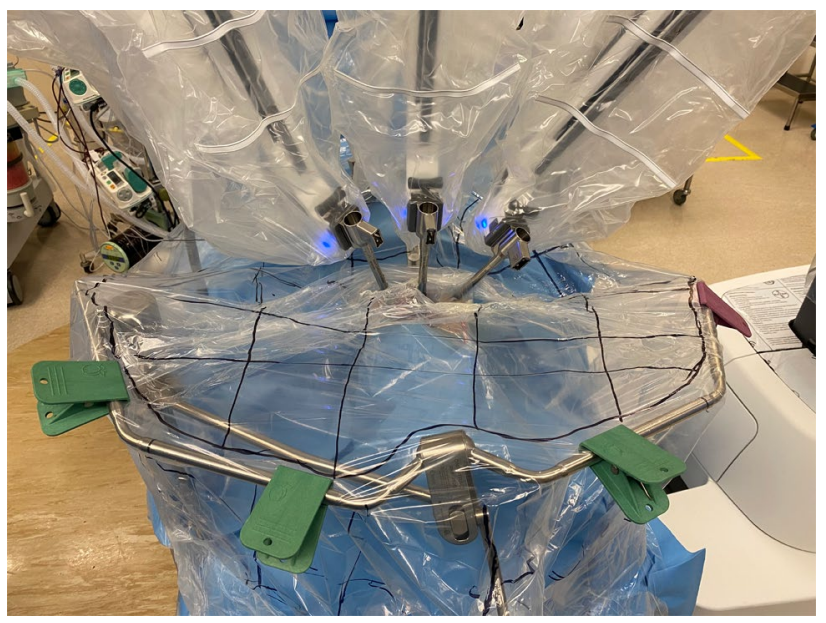

Fig. 3 Placement of grids on plastic sheet on completion of TORS

(Leica Microsystems GmbH, Germany) [12]. The plastic sheets and face shields were discarded once counting was complete.

Operative diagnosis and procedure; size, number and distribution of droplets on plastic sheets and face shields for each party were documented.

\section{Results}

Eight patients with no clinical evidence of COVID-19 underwent TORS. Three patients underwent TORS bilateral tonsillectomy and tongue base mucosectomy for cervical nodal metastatic squamous cell carcinoma of unknown origin; three patients underwent TORS bilateral tonsillectomy for incidental finding of asymmetrical fluorodeoxyglucose (FDG) uptake on whole-body PET scan; two patients underwent TORS excision of tongue base tumour. Droplet contamination was noted on all plastic sheets $(n=8)$. Droplet size ranged from $0.2 \mathrm{~mm}$ to $3.2 \mathrm{~mm}$. Droplet contamination was most severe over the central surface for all patients with an average of $97.2 \%(91.7-100.0 \%)$ followed by the right lateral surface at $2.8 \%(0.0-8.3 \%)$ There was no droplet contamination noted over the vertex and left lateral surfaces (Table 1). Droplet contamination was mainly over the central part of the plastic drape overlying the site of operation in the oral cavity. Total droplet count was highest along the centremost column $\mathrm{E}$ at $33.3 \%(n=31)$. Droplet count decreased towards the periphery on both sides $-26.9 \%(n=25), 6.5 \%$ $(n=6)$ and $3.2 \%(n=3)$ at columns D, C and B respectively towards the right, and $22.6 \%(n=21)$ and $7.5 \%(n=7)$ at columns $\mathrm{F}$ and $\mathrm{G}$ respectively towards the left. There was no droplet contamination noted along columns A, H and I (Table 2). 


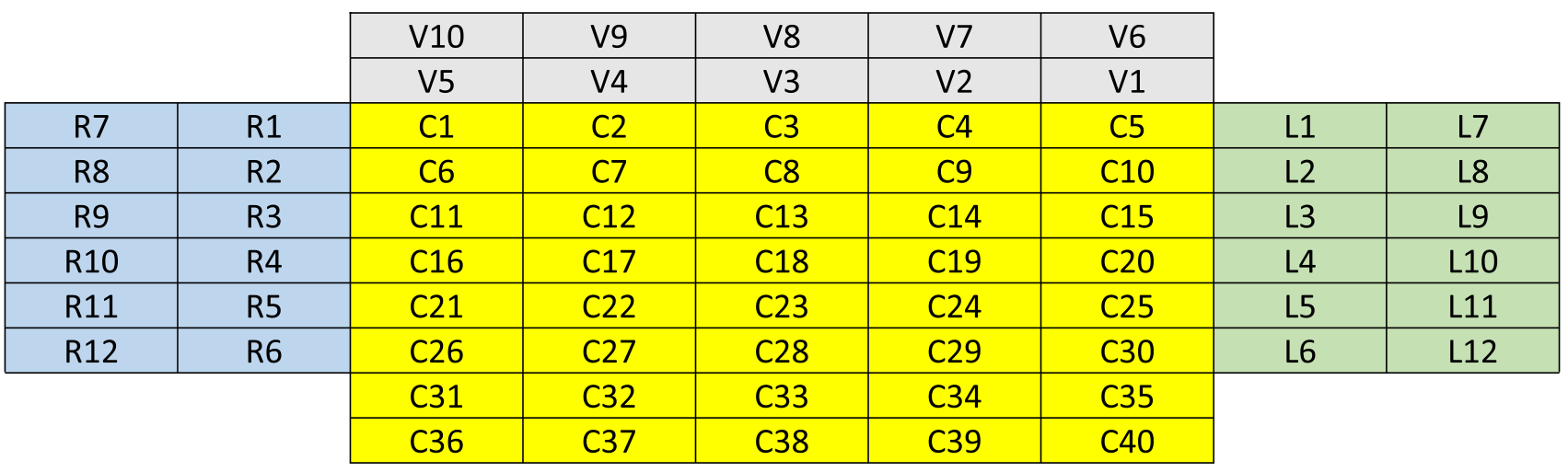

Blue Area of plastic drape on surgeon's side / patient's right side, labelled R1-12.

Yellow $\quad$ Area of plastic drape over center of operating field labelled C1-40.

Green Area of plastic drape opposite to surgeon / patient's left side, labelled L1-12.

Grey $\quad$ Area of plastic drape over vertex, labelled V1-10.

Fig. 4 Labelling of grids on plastic drape for TORS

\section{Discussions}

SARS-CoV-2 is transmitted through close contact and droplets. Airborne transmission may occur during AGP. TORS for resection of tumours spanning the nasopharynx, oropharynx, laryngotracheal apparatus and pharyngo-esophagus poses risks of aerosolization of blood and irrigation fluids generated by cautery device. Careful patient selection, full barrier protection, limiting operative personnel to the minimal and most experienced staff, and attention to operative details can help to minimise aerosol spillage and viral transmission: a team comprising of the most experienced staff minimises operating time, blood loss, duration of aerosol exposure, peri-operative morbidity and hospital stay, ultimately reducing the chance of viral transmission to health care providers and other patients. Careful tissue dissection, avoidance of unnecessary irrigation and vigilant suction of secretions, blood and irrigation fluid, and careful removal and placement of robotic surgical instruments through robotic cannulae can help to minimise aerosol spillage and viral transmission.

The use of an impermeable surface draped over the operative field has been described for endonasal endoscopic approaches and TORS for resection of pathologies in the upper aerodigestive tract, which acted as an additional physical barrier against aerosol spillage. These included the use of plastic sheets and latex gloves. Fenestrations were made on the drape to cater for camera port and instrument arms [13-15]. Smoke evacuator suction system could be placed under the drape to further reduce viral load [16]. However, movement of robotic arms would enlarge the fenestrations, which in turn would lead to increased chance of aerosol spillage around each cannula and viral transmission.

In this study, we proposed the use of sterile supports and the use of two clear plastic sheets draped over the operative field, with water-tight seal around each robotic cannula. The rationale was to create a water-tight, spacious and sterile closed environment which enabled free movement of robotic arms, and for the assistant surgeon to work in whilst preventing droplet and aerosol spillage, ultimately reducing the chance of viral transmission. To our knowledge, such a setup has not been described in literature.

In order to diminish risk of droplet and aerosol contamination, the following steps were taken prior to docking: (1) ensure that the cuff of the endotracheal tube was inflated with no evidence of air leak (2) a Fr 16 Nelaton suction catheter connected to a surgical suction system with smoke and HEPA filters was placed in the remaining nostril for suctioning of saliva, blood, diathermy smoke and aerosols generated during the operation. The position of the Nelaton tube could be adjusted as required throughout the operation [17].

After docking of robotic arms and deployment of endowrists, the Wishbone ${ }^{\circledR}$ Frame was positioned and fixed with the Omni-Flex ${ }^{\circledR}$ Post. This was to ensure that neither the Omni-Flex ${ }^{\circledR}$ Post nor Wishbone ${ }^{\circledR}$ Frame would hinder docking and/or result in inadvertent collisions with the robotic arms. The Wishbone ${ }^{\circledR}$ Frame was positioned well above 
Table 1 Droplet count and distribution for TORS patients

\begin{tabular}{|c|c|c|c|c|c|c|c|c|}
\hline Patient 1 & & V10 & V9 & V8 & V7 & V6 & & \\
\hline & & V5 & V4 & V3 & V2 & V1 & & \\
\hline R7 & $\mathrm{R} 1$ & $\mathrm{C} 1$ & $\mathrm{C} 2$ & $\mathrm{C} 3$ & $\mathrm{C} 4$ & 1 & $\mathrm{~L} 1$ & L7 \\
\hline R8 & $\mathrm{R} 2$ & C6 & 1 & 2 & 1 & $\mathrm{C} 10$ & $\mathrm{~L} 2$ & L8 \\
\hline R9 & $\mathrm{R} 3$ & $\mathrm{C} 11$ & $\mathrm{C} 12$ & 1 & $\mathrm{C} 14$ & $\mathrm{C} 15$ & L3 & L9 \\
\hline R10 & $\mathrm{R} 4$ & 1 & 1 & 1 & 2 & 1 & L4 & L10 \\
\hline R11 & 1 & $\mathrm{C} 21$ & 1 & $\mathrm{C} 23$ & $\mathrm{C} 24$ & $\mathrm{C} 25$ & L5 & L11 \\
\hline \multirow[t]{3}{*}{$\mathrm{R} 12$} & R6 & $\mathrm{C} 26$ & $\mathrm{C} 27$ & $\mathrm{C} 28$ & 1 & C30 & L6 & L12 \\
\hline & & $\mathrm{C} 31$ & C 32 & C33 & $\mathrm{C} 34$ & C35 & & \\
\hline & & $\mathrm{C} 36$ & C37 & C 38 & C39 & $\mathrm{C} 40$ & & \\
\hline \multirow[t]{2}{*}{ Patient 2} & & V10 & V9 & V8 & V7 & V6 & & \\
\hline & & V5 & V4 & V3 & $\mathrm{V} 2$ & V1 & & \\
\hline R7 & $\mathrm{R} 1$ & $\mathrm{C} 1$ & $\mathrm{C} 2$ & $\mathrm{C} 3$ & 1 & $\mathrm{C} 5$ & $\mathrm{~L} 1$ & L7 \\
\hline R8 & $\mathrm{R} 2$ & 1 & $\mathrm{C} 7$ & 1 & C9 & 1 & $\mathrm{~L} 2$ & L8 \\
\hline R9 & $\mathrm{R} 3$ & $\mathrm{C} 11$ & 1 & 2 & 1 & $\mathrm{C} 15$ & L3 & L9 \\
\hline R10 & 1 & C16 & 1 & 1 & C19 & $\mathrm{C} 20$ & L4 & L10 \\
\hline R11 & R5 & 1 & $\mathrm{C} 22$ & $\mathrm{C} 23$ & 1 & $\mathrm{C} 25$ & L5 & L11 \\
\hline \multirow[t]{3}{*}{$\mathrm{R} 12$} & R6 & $\mathrm{C} 26$ & $\mathrm{C} 27$ & $\mathrm{C} 28$ & $\mathrm{C} 29$ & $\mathrm{C} 30$ & L6 & L12 \\
\hline & & C31 & $\mathrm{C} 32$ & C33 & $\mathrm{C} 34$ & C35 & & \\
\hline & & $\mathrm{C} 36$ & C37 & C38 & C39 & $\mathrm{C} 40$ & & \\
\hline \multirow[t]{2}{*}{ Patient 3} & & V10 & V9 & V8 & V7 & V6 & & \\
\hline & & V5 & V4 & V3 & $\mathrm{V} 2$ & V1 & & \\
\hline R7 & $\mathrm{R} 1$ & $\mathrm{C} 1$ & $\mathrm{C} 2$ & 1 & $\mathrm{C} 4$ & $\mathrm{C} 5$ & L1 & L7 \\
\hline R8 & 1 & C6 & 1 & 1 & $\mathrm{C} 9$ & 1 & L2 & L8 \\
\hline R9 & $\mathrm{R} 3$ & C11 & 1 & 2 & 1 & $\mathrm{C} 15$ & L3 & L9 \\
\hline R10 & $\mathrm{R} 4$ & $\mathrm{C} 16$ & 1 & $\mathrm{C} 18$ & 1 & $\mathrm{C} 20$ & L4 & L10 \\
\hline R11 & R5 & $\mathrm{C} 21$ & $\mathrm{C} 22$ & 1 & $\mathrm{C} 24$ & $\mathrm{C} 25$ & L5 & L11 \\
\hline \multirow[t]{3}{*}{$\mathrm{R} 12$} & R6 & $\mathrm{C} 26$ & $\mathrm{C} 27$ & $\mathrm{C} 28$ & $\mathrm{C} 29$ & $\mathrm{C} 30$ & L6 & L12 \\
\hline & & C31 & $\mathrm{C} 32$ & C33 & $\mathrm{C} 34$ & C35 & & \\
\hline & & $\mathrm{C} 36$ & C37 & C38 & C39 & $\mathrm{C} 40$ & & \\
\hline \multirow[t]{2}{*}{ Patient 4} & & V10 & V9 & V8 & V7 & V6 & & \\
\hline & & V5 & V4 & V3 & $\mathrm{V} 2$ & V1 & & \\
\hline R7 & $\mathrm{R} 1$ & $\mathrm{C} 1$ & $\mathrm{C} 2$ & $\mathrm{C} 3$ & $\mathrm{C} 4$ & C5 & L1 & L7 \\
\hline R8 & $\mathrm{R} 2$ & 1 & 1 & 1 & 1 & 1 & $\mathrm{~L} 2$ & L8 \\
\hline R9 & $\mathrm{R} 3$ & C11 & $\mathrm{C} 12$ & 1 & $\mathrm{C} 14$ & $\mathrm{C} 15$ & L3 & L9 \\
\hline R10 & $\mathrm{R} 4$ & $\mathrm{C} 16$ & 1 & $\mathrm{C} 18$ & 1 & 1 & $\mathrm{~L} 4$ & L10 \\
\hline R11 & $\mathrm{R} 5$ & $\mathrm{C} 21$ & $\mathrm{C} 22$ & 1 & $\mathrm{C} 24$ & $\mathrm{C} 25$ & L5 & L11 \\
\hline \multirow[t]{3}{*}{$\mathrm{R} 12$} & R6 & $\mathrm{C} 26$ & 1 & $\mathrm{C} 28$ & $\mathrm{C} 29$ & C30 & L6 & L12 \\
\hline & & $\mathrm{C} 31$ & $\mathrm{C} 32$ & C33 & C34 & C35 & & \\
\hline & & C36 & C37 & C38 & C39 & $\mathrm{C} 40$ & & \\
\hline \multirow[t]{2}{*}{ Patient 5} & & V10 & V9 & V8 & V7 & V6 & & \\
\hline & & V5 & V4 & V3 & V2 & V1 & & \\
\hline R7 & $\mathrm{R} 1$ & $\mathrm{C} 1$ & $\mathrm{C} 2$ & $\mathrm{C} 3$ & $\mathrm{C} 4$ & $\mathrm{C} 5$ & L1 & L7 \\
\hline R8 & $\mathrm{R} 2$ & C6 & 1 & 1 & 1 & $\mathrm{C} 10$ & L2 & L8 \\
\hline R9 & R3 & 1 & 1 & 1 & 2 & 1 & L3 & L9 \\
\hline R10 & $\mathrm{R} 4$ & C16 & 1 & 1 & 1 & $\mathrm{C} 20$ & L4 & L10 \\
\hline R11 & R5 & $\mathrm{C} 21$ & $\mathrm{C} 22$ & 1 & $\mathrm{C} 24$ & $\mathrm{C} 25$ & L5 & L11 \\
\hline $\mathrm{R} 12$ & R6 & $\mathrm{C} 26$ & $\mathrm{C} 27$ & $\mathrm{C} 28$ & $\mathrm{C} 29$ & C30 & L6 & L12 \\
\hline
\end{tabular}


Table 1 (continued)

\begin{tabular}{|c|c|c|c|c|c|c|c|c|}
\hline \multicolumn{2}{|l|}{ Patient 5} & \multirow{2}{*}{$\frac{\mathrm{V} 10}{\mathrm{C} 31}$} & \multirow{2}{*}{$\frac{\mathrm{V} 9}{\mathrm{C} 32}$} & \multirow{2}{*}{$\frac{\mathrm{V} 8}{\mathrm{C} 33}$} & \multirow{2}{*}{$\frac{\mathrm{V} 7}{\mathrm{C} 34}$} & \multicolumn{3}{|l|}{ V6 } \\
\hline & & & & & & C35 & & \\
\hline & & C36 & $\mathrm{C} 37$ & C38 & C39 & $\mathrm{C} 40$ & & \\
\hline \multirow[t]{2}{*}{ Patient 6} & & V10 & V9 & V8 & V7 & V6 & & \\
\hline & & V5 & V4 & V3 & $\mathrm{V} 2$ & V1 & & \\
\hline R7 & $\mathrm{R} 1$ & $\mathrm{C} 1$ & $\mathrm{C} 2$ & $\mathrm{C} 3$ & $\mathrm{C} 4$ & $\mathrm{C} 5$ & L1 & $\mathrm{L} 7$ \\
\hline $\mathrm{R} 8$ & $\mathrm{R} 2$ & C6 & 1 & 1 & 1 & $\mathrm{C} 10$ & L2 & L8 \\
\hline R9 & R3 & $\mathrm{C} 11$ & 2 & 2 & $\mathrm{C} 14$ & $\mathrm{C} 15$ & L3 & L9 \\
\hline $\mathrm{R} 10$ & R4 & C16 & 1 & 1 & C19 & $\mathrm{C} 20$ & L4 & L10 \\
\hline $\mathrm{R} 11$ & R5 & $\mathrm{C} 21$ & 1 & $\mathrm{C} 23$ & $\mathrm{C} 24$ & $\mathrm{C} 25$ & L5 & L11 \\
\hline \multirow[t]{3}{*}{$\mathrm{R} 12$} & R6 & $\mathrm{C} 26$ & $\mathrm{C} 27$ & $\mathrm{C} 28$ & $\mathrm{C} 29$ & $\mathrm{C} 30$ & L6 & L12 \\
\hline & & C31 & $\mathrm{C} 32$ & $\mathrm{C} 33$ & C34 & $\mathrm{C} 35$ & & \\
\hline & & $\mathrm{C} 36$ & $\mathrm{C} 37$ & $\mathrm{C} 38$ & C39 & $\mathrm{C} 40$ & & \\
\hline \multirow[t]{2}{*}{ Patient 7} & & V10 & V9 & V8 & V7 & V6 & & \\
\hline & & V5 & V4 & V3 & V2 & V1 & & \\
\hline R7 & R1 & $\mathrm{C} 1$ & $\mathrm{C} 2$ & $\mathrm{C} 3$ & $\mathrm{C} 4$ & $\mathrm{C} 5$ & L1 & L7 \\
\hline $\mathrm{R} 8$ & $\mathrm{R} 2$ & C6 & $\mathrm{C} 7$ & 1 & 1 & $\mathrm{C} 10$ & L2 & L8 \\
\hline R9 & R3 & $\mathrm{C} 11$ & $\mathrm{C} 12$ & 2 & 1 & $\mathrm{C} 15$ & L3 & L9 \\
\hline R10 & R4 & $\mathrm{C} 16$ & 2 & 2 & C19 & $\mathrm{C} 20$ & L4 & L10 \\
\hline R11 & R5 & $\mathrm{C} 21$ & $\mathrm{C} 22$ & $\mathrm{C} 23$ & 1 & $\mathrm{C} 25$ & L5 & L11 \\
\hline \multirow[t]{3}{*}{ R12 } & R6 & $\mathrm{C} 26$ & $\mathrm{C} 27$ & $\mathrm{C} 28$ & $\mathrm{C} 29$ & $\mathrm{C} 30$ & L6 & L12 \\
\hline & & $\mathrm{C} 31$ & $\mathrm{C} 32$ & $\mathrm{C} 33$ & C34 & $\mathrm{C} 35$ & & \\
\hline & & C36 & $\mathrm{C} 37$ & C38 & C39 & $\mathrm{C} 40$ & & \\
\hline \multirow[t]{2}{*}{ Patient 8} & & V10 & V9 & V8 & V7 & V6 & & \\
\hline & & V5 & V4 & V3 & V2 & V1 & & \\
\hline R7 & R1 & $\mathrm{C} 1$ & $\mathrm{C} 2$ & $\mathrm{C} 3$ & $\mathrm{C} 4$ & C5 & L1 & L7 \\
\hline R8 & $\mathrm{R} 2$ & C6 & C7 & C8 & C9 & C10 & L2 & L8 \\
\hline R9 & R3 & 1 & 2 & 2 & 1 & C15 & L3 & L9 \\
\hline R10 & R4 & C16 & 2 & C18 & 1 & C20 & L4 & L10 \\
\hline R11 & R5 & $\mathrm{C} 21$ & $\mathrm{C} 22$ & $\mathrm{C} 23$ & $\mathrm{C} 24$ & $\mathrm{C} 25$ & L5 & L11 \\
\hline \multirow[t]{3}{*}{$\mathrm{R} 12$} & R6 & C26 & $\mathrm{C} 27$ & C28 & C29 & C30 & L6 & L12 \\
\hline & & C31 & C32 & C33 & C34 & C35 & & \\
\hline & & C36 & C37 & C38 & C39 & $\mathrm{C} 40$ & & \\
\hline
\end{tabular}

patient's vertex and extended to ensure maximal angulation at each joint, which in turn increased working space. The height of the Wishbone ${ }^{\circledR}$ Frame could be adjusted by the surgeon to ensure adequate working space of the robotic arms and assistant surgeon whilst not obstructing anaesthetist's access to the endo-tracheal tube if need be. The Omni-Flex ${ }^{\circledR}$ Post was fixed on the same side as the Boyle-Davis support, usually to patient's bedside on the left so as to ensure maximal working space for the assistant surgeon on the right side.

Two clear sterile plastic sheets re-inforced at the junction with adhesive $3 \mathrm{M}$ tapes were used to create a giant sterile drape over the operating field, whilst accommodating the three moving robotic arms. Additional adhesive $3 \mathrm{M}$ tape was used to re-inforce three-point junctions between the two plastic sheets and each of the three robotic cannulae to create a water-tight seal. The plastic sheets were draped loosely over the Wishbone ${ }^{\circledR}$ and Boyle-Davis suspension frames to allow for stretching and movement of the plastic sheet with the three robotic arms. Such a set-up was deemed superior than using one single plastic sheet with three fenestrations to cater for the robotic arms, as the moving robotic arms would enlarge the fenestrations, which in turn would allow droplet and aerosol spillage. Cranial, caudal and left lateral edges of the giant plastic sterile drape was taped to surgical drapes to create a closed sterile environment using adhesive $3 \mathrm{M}$ tape, leaving the right lateral edge untapped whereby the assistant surgeon worked under. Furthermore, placement of negative pressure surgical suction system opposite the 
Table 2 Total droplet count and distribution of droplets for TORS patients

\begin{tabular}{rrrrrrrrrrr}
\hline & A & B & C & D & E* & F & G & H & I & \\
\hline 1 & 0 & 1 & 1 & 3 & 4 & 4 & 2 & 0 & 0 & 15 \\
2 & 0 & 1 & 2 & 2 & 4 & 3 & 1 & 0 & 0 & 13 \\
3 & 0 & 1 & 0 & 3 & 5 & 2 & 1 & 0 & 0 & 12 \\
4 & 0 & 0 & 1 & 3 & 3 & 2 & 2 & 0 & 0 & 11 \\
5 & 0 & 0 & 1 & 3 & 4 & 4 & 1 & 0 & 0 & 13 \\
6 & 0 & 0 & 0 & 5 & 4 & 1 & 0 & 0 & 0 & 10 \\
7 & 0 & 0 & 0 & 2 & 5 & 3 & 0 & 0 & 0 & 10 \\
8 & 0 & 0 & 1 & 4 & 2 & 2 & 0 & 0 & 0 & 9 \\
& 0 & 3 & 6 & 25 & 31 & 21 & 7 & 0 & 0 & 93 \\
\hline
\end{tabular}

Column A: R7-12

Column B: R1-6

Column C: V10, V5, C1, C6, C11, C16, C21, C26, C31, C36

Column D: V9, V4, C2, C7, C12, C17, C22, C27, C32, C37

Column E: V8, V3, C3, C8, C13, C18, C23, C28, C33, C38 (*Centre-most column)

Column F: V7, V2, C4, C9, C14, C19, C24, C29, C34, C39

Column G: V6, V1, C5, C10, C15, C20, C25, C30, C35, C40

Column H: L1-6

Column I: L7-12 assistant surgeon enabled safe removal of smoke and aerosols generated during the procedure which further decreased risk of viral transmission, in addition to prevention of fogging and resultant impaired visibility.

Droplet contamination was most severe over the central surface which was directly over the operative field in the oral cavity (97.2\%). There was minimal droplet contamination on the right lateral surface (2.8\%), whereby the plastic sheet acted as a hood protecting the assistant surgeon against droplet and aerosol contamination. No droplet contamination was noted on the vertex and contralateral surfaces for all patients. Face shields of the operating surgeon on docking; and face shields of the assistant surgeon and scrub nurse throughout the operation were clear of droplet contamination. Although aerosol particles were too small to be visualised under the surgical microscope, the ability to contain droplets under the water-tight sealed impermeable plastic drapes suggested that such a set-up not only prevents droplet spillage, but it could also help to reduce aerosol spillage during TORS. Proper disposal of plastic drapes were imperative in the prevention of viral transmission to health care workers.

Results from our preliminary study suggested that the proposed set-up could effectively prevent droplet and aerosol contamination during TORS. At such times of global PPE shortage, ace shield may be spared given adequate eye protection and respirator. Such an approach can also be advocated for other AGP and endoscopic head and neck surgical procedures in an attempt to reduce viral transmission to health care providers.

Larger scale studies with more patients and operating surgeons is warranted to justify such recommendations. Ideally commercially made sterile plastic drapes incorporating cannulae covers and closed systems with negative pressure would help to further decrease spillage around cannulae during movement of robotic arms. Application of fluorescent dye to mucosal lining and detection of spillage with ultraviolet light may give a better reflection of the extent of both droplet and aerosol spillage [16].

\section{Conclusion}

The creation of a water-tight, sterile and closed environment with sterile plastic drapes may help to prevent droplet and aerosol spillage when performing TORS for all unknown, suspected and confirmed COVID-19 patients, which in turn helps to reduce the chance of viral transmission to health care providers. Such a set-up is functional, readily available and cost effective. The aforementioned approach should be considered to support safe clinical practice and efficient use of resources during the COVID-19 pandemic.

Funding No funding was received.

\section{Compliance with ethical standards}

Conflict of interest All authors (Dr. Velda Chow, Dr. Jimmy Chan, Dr. Melody Wong, Dr. Stanley Wong and Dr. Raymond Tsang) declare that they have no conflict of interest.

Ethical approval All procedures followed were in accordance with the ethical standards of the responsible committee on human experimenta- 
tion (institutional and national) and with the Helsinki Declaration of 1975, as revised in 2000 .

Informed consent Informed consent was obtained from all patients for being included in the study.

\section{References}

1. Chan JY (2015) Surgical salvage of recurrent nasopharyngeal carcinoma. Curr Oncol Rep 17(3):433. https://doi.org/10.1007/ s11912-014-0433-x ((PMID: 25687806))

2. Tsang RK, To VS, Ho AC, Ho WK, Chan JY, Wei WI (2015) Early results of robotic assisted nasopharyngectomy for recurrent nasopharyngeal carcinoma. Head Neck 37:788-793 ((Epub 2014 Jun 19 PMID: 24604758)

3. Hinni ML, Nagel T, Howard B (2015) Oropharyngeal cancer treatment: the role of transoral surgery. Curr Opin Otolaryngol Head Neck Surg 23(2):132-138. https://doi.org/10.1097/MOO.00000 00000000143 ((PMID: 25761152))

4. Gallitto M, Sindhu K, Wasserman I, De B, Gupta V, Miles BA et al (2019) Trimodality therapy for oropharyngeal cancer in the TORS era: Is there a cohort that may benefit? Head Neck 41(9):3009-3022. https://doi.org/10.1002/hed.25779 ((Epub 2019 Apr 17 PMID: 30997703))

5. Zou L, Ruan F, Huang M, Liang L, Huang H, Hong Z et al (2020) SARS-CoV-2 viral load in upper respiratory specimens of infected patients. N Engl J Med. https://doi.org/10.1056/NEJMc2001737 ((Epub 2020b 19. PMID: 32074444))

6. Lai C-C, Liu Y-H, Wang C-Y, Wang Y-H, Hsueh S-C, Yen M-Y et al (2020) Asymptomatic carrier state, acute respiratory disease, and pneumonia due to severe acute respiratory syndrome coronavirus 2 (SARSCoV-2): facts and myths. J Microbiol Immunol Infect 2:1-36. https://doi.org/10.1016/j.jmii.2020.02.012 ((Epub 2020 Mar 4 PMID: 32173241))

7. Ai T, Yang Z, Hou H, Zhan C, Chen C, Lv W et al (2019) Correlation of Chest CT and RT-PCR testing in coronavirus disease (COVID-19) in China: a report of 1014 cases. Radiology 20:200642. https://doi.org/10.1148/radiol.2020200642 ((Epub 2020 Feb 26 PMID: 32101510))

8. US Centers for disease control and prevention. Interim infection prevention and control recommendations for patients with suspected or confirmed coronavirus disease (COVID-19) in healthcare settings. [Available. From: https://www.cdc.gov/coronaviru s/2019-ncov/infection-control/control-recommendations.html]. Accessed 26 Nov 2020
9. Centre for Health Protection. Latest situation of coronavirus disease (COVID-19) in Hong Kong. [Available from: https://chpdashboard.geodata.gov.hk/covid-19/en.html]

10. World Health Organisation (WHO). Rational use of personal protective equipment for coronavirus disease (COVID-19) and considerations during severe shortages. Interim guidance 2020. [Available from: https://apps.who.int/iris/bitstream/handle/10665 1331695/WHO-2019-nCov-IPC_PPE_use-2020.3-eng.pdf]. Accessed 26 Nov 2020

11. Chow VLY, Chan JYW, Ho VWY, Lee GCC, Wong MMK, Wong STS et al (2020) Conservation of personal protective equipment for head and neck cancer surgery during COVID-19 pandemic. Head Neck 42(6):1187-1193. https://doi.org/10.1002/hed.26215 ((Epub 2020 Apr 29PMID: 32342543))

12. Chow VLY, Chan JYW, Ho VWY, Pang SSY, Lee GCC, Wong MMK et al (2020) Tracheostomy during COVID-19 pandemicNovel approach. Head Neck 42(7):1367-1373. https://doi. org/10.1002/hed.26234 ((Epub 2020 May 6PMID: 32358855))

13. Ghazali N, Attardo G, Markose G (2020) Modification of the microscope drape to provide a closed surgical field in transoral robotic surgery. Br J Oral Maxillofac Surg 58(7):867-868. https ://doi.org/10.1016/j.bjoms.2020.06.022 ((Epub 2020 Jul 4))

14. Meccariello G, Cammaroto G, Iannella G, Capaccio P, Pelucchi S, Vicini C (2020) Minimizing contagion risks of COVID-19 during transoral robotic surgery. Laryngoscope 130(11):2593-2594. https ://doi.org/10.1002/lary.28847

15. Helman SN, Soriano RM, Tomov ML, Serpooshan V, Levy JMG et al (2020) Ventilated upper airway endoscopic endonasal procedure mask: surgical safety in the COVID-19 Era. Oper Neurosurg (Hagerstown) 19(3):271-280. https://doi.org/10.1093/ons/opaa1 68

16. David AP, Jiam NT, Reither JM, Gurrola JG, Aghi MK, El-Sayed IH (2020) Endoscopic skull base and transoral surgery during COVID-19 pandemic: Minimizing droplet spread with negative-pressure otolaryngology viral isolation drape. Head Neck 42(7):1577-1582. https://doi.org/10.1002/hed.26239 ((Epub 2020 May 30.PMID: 32358853))

17. Chow VL, Chan JY, Wong ST, Wei WI (2020) Recommendations for surgical management of recurrent nasopharyngeal carcinoma during COVID-19 pandemic. Laryngoscope Investig Otolaryngol 1:1-5. https://doi.org/10.1002/lio2.417 ((PMID: 32596489))

Publisher's Note Springer Nature remains neutral with regard to jurisdictional claims in published maps and institutional affiliations. 